\title{
Analysis of Alcohol Consumption and Death Rates Resulting from Alcohol Consumption in EU and OECD Countries
}

\author{
MEGYESIOVÁ, S. ${ }^{1}$, GAVUROVÁ, B. ${ }^{2}$
}

1| University of Economics in Bratislava, Faculty of Business Economics, Košice, Slovakia

2 | Tomas Bata University, Faculty of Management and Economics, Centre for Applied Economic Research, Zlín, Czech Republic
Citation | Megyesiová, S., Gavurová, B. (2019). Multivariate Analysis of Alcohol Consumption and Death Rates Resulting from Alcohol Consumption in EU and OECD Member States. Adiktologie, 19(4), 179-187;

doi 10.35198/01-2019-004-0002.
BACKGROUND: Excessive alcohol consumption has a negative impact on the social or physical lives of human beings and can lead to death or accidents. AIM: The article deals with a multivariate analysis of per capita alcohol consumption and standardized death rates (SDR) from liver cirrhosis, cancer, and road traffic crash deaths resulting from alcohol consumption. The life expectancies in $41 \mathrm{EU}$ and OECD countries were also included in the analysis. METHODS: Correlation analysis helped to detect the significant linear relationship between indicators. Principal component analysis was used to calculate uncorrelated main components that were applied for the next step of the analysis, i.e. cluster analysis. Finally, cluster analysis was used to create groups of countries, i.e. isolated clusters of countries with similar levels of selected indicators. RESULTS: The average pure alcohol consumption per capita in the 41 OECD and EU countries declined from 9.8 litres in 2000 to 9.3 litres in 2016. More than $40 \%$ of the total alcohol consumption concerned the consumption of beer. A statistically significant positive correlation was discovered between alcohol consumption and the mortality rates resulting from alcohol consumption caused by liver cirrhosis, cancer, and road traffic crash deaths. CONCLUSIONS: The cluster with the lowest alcohol consumption was created with only two countries (Israel, Turkey), where the alcohol consumption was as low as 2 litres per capita. On the other hand, the cluster with the highest alcohol consumption in 2000 (12.9 litres per capita) included 12 European countries. Their mortality resulting from alcohol consumption was in the "middle" between the clusters. Thus, the cluster with the worst or highest alcohol consumption was not the worst in terms of mortality resulting from alcohol consumption. To detect the most important factors behind this will be a new challenge for subsequent research.

\section{Keywords | Multivariate Analysis - Alcohol Consumption - Age-standardized Death Rate - Life Expectancy - European Union - OECD} RV0/2020: "Economic quantification of marketing processes that focus on the increase in value for a patient in the process of the creation of a system to measure and control efficiency in health facilities in the Czech Republic". 


\section{INTRODUCTION}

Heavy alcohol consumption has a strong and negative impact on the social, economic, or psychological situation of a human being. Excessive alcohol consumption belongs among the risk factors for health; it harms health, shortens lives, causes morbidity, and leads to death. Heavy alcohol use increases the risk of abdominal obesity (Huang et al., 2015), is positively associated with an increased risk of hypertension (Ikehara \& Iso, 2020), leads to alcoholic liver diseases and alcohol use disorders (Rehm \& Shield, 2019), and increases morbidity and mortality (Grabauska et al., 2009; Mravčík et al., 2019; Gavurova et al., 2019). Alcohol consumption in adolescence is associated with adverse physical health (König et al., 2018). After some decades the regular drinking of too much alcohol can lead to the development of serious illnesses, for example cancer, stroke, heart disease, liver cirrhosis, alcoholic hepatitis, brain damage, and damage to the nervous system, and it can contribute to death (NIAAA; NHS; OECD; Han, 2019). It is indisputable that the uncontrolled heavy drinking of alcohol has a detrimental effect on people's health and social behaviour. But what about light regular drinking? Evidence exists that light to moderate drinking is associated with beneficial effects on ischemic heart disease and ischemic stroke (Rehm \& Roerecke, 2017), and the moderate consumption of alcohol is inversely related to coronary disease (Castelnuovo, 2006); the alcohol intake should be limited to 1-2 drinks per day for women and 2-4 drinks per day for men. Moderate ethanol intake from any type of beverage improves lipoprotein metabolism and lowers the risk of cardiovascular mortality (German \& Walzem, 2000), and the moderate consumption of red wine has beneficial effects on health, as red wine has proven antioxidant and anti-inflammatory effects (Castaldo et al., 2019). But more relevant research is needed to be able to assess the overall benefit-risk ratio of alcohol consumption in order to provide information about safe or low-risk drinking levels (Roerecke \& Rehm, 2012).

The main aim of this article is a multivariate analysis of pure alcohol consumption per capita in the OECD and EU Member States. The alcohol consumption per capita (15+ years) in litres of pure alcohol over a calendar year comes from the Global Information System on Alcohol and Health tool. The alcohol consumption dataset was extended by the structure of the alcohol consumption, by the age-standardized mortality rates (15+) from liver cirrhosis, cancer, and road traffic crash deaths caused by alcohol consumption, and also life expectancies at birth (LE). The mortality datasets and the LE come from the Global Health Observatory database. The analysis was performed for a combination of seasons. The starting level of per capita pure alcohol consumption in 2000 was combined with the SDR (15+) in the year 2016, as it is expected that the mortality from diseases caused by alcohol consumption happens after more than five years of heavy alcohol consumption. The per capita alcohol consumption in 2016 was included into the analysis too, and it allows the trend of alcohol consumption to be seen; the life expectancies at birth in 2000 and 2016 tell us a lot about the healthcare situation in different countries and also tell us a lot about the lifestyle of the population in the EU and/ or OECD countries. For the analysis, all of the EU Member States and OECD countries were selected. As some of the countries are members of both communities, altogether 41 countries were included in the analysis.

\section{DATA AND METHODOLOGY}

The analysis focused on multivariate analysis of the following indicators: total recorded alcohol consumption per capita (15+ years), age-standardized death rates (15+) from liver cirrhosis, from cancer (15+), and from road traffic crash deaths $(15+)$ resulting from alcohol consumption, life expectancy at birth, and wine consumption as a percentage of total alcohol consumption. The age-standardized death rates (SDR) are expressed per 100,000 citizens aged 15 and over. The SDR are calculated separately for males and females because of the different death rates for each sex. Each of the indicators comes from the database of the World Health Organization, specifically from the Global Information System on Alcohol and Health and from the Global Health Observatory.

The aim of the study was to merge, for analytical purposes, the alcohol consumption per capita levels with some negative outcomes of alcohol consumption. One very negative outcome of alcohol consumption is death resulting from alcohol consumption and therefore the age-SDR of persons aged 15 and over were considered for analysis. Three different kinds of death rates were used to describe the situation in mortality caused by alcohol consumption. To calculate the age-SDR (15+) resulting from alcohol consumption the alcohol-attributable fractions (15+) were used (Global Health Observatory). Since it takes five or more years to develop an illness (liver cirrhosis or cancer) that leads to death, in the analysis the per capita consumption of pure alcohol in 2000 was combined with the latest available specific mortality rates for 2016. The interest of the study was to discover the trend of alcohol consumption and therefore the indicator of registered pure alcohol consumption per capita in 2016 was also included into the analysis. As the road traffic crash deaths caused by alcohol consumption are related to the alcohol consumption in the specific period, the age-SDR from road traffic crash deaths (15+) resulting from alcohol consumption in 2016 was selected for the multivariate analysis too. In order to obtain an overall picture of longevity, the life expectancies at birth for 2000 and 2016 were also chosen for multivariate analysis.

The Pearson's correlation coefficient was calculated to detect the linear relationship between the selected variables. A strong correlation, either positive or negative, is a sign of a linear association between a pair of variables. In the analysis of socio-economic indicators there usually exist some pairs of variables that are significantly correlated. Cluster analysis (CA) is a multivariate technique that is able, by using two or more indicators, to form isolated clusters of objects, in our case clusters of countries. The countries in a specific cluster are similar to each other ac- 
cording to the values of the indicators that were analysed. The CA, however, expects uncorrelated variables; otherwise the results of the CA are incorrect. If the correlation is statistically significant before the CA a different multivariate analysis must be performed, i.e. principal component analysis (PCA). PCA is a dimension reduction method that forms a smaller number of linear combinations of indicators being analysed. The "new latent" variables should account for most of the variance in the correlation matrix pattern (Dillon \& Goldstein, 1984; Statistics solutions). It means that these new variables, components, are used in the analysis instead of correlated indicators, correlated variables. The component analysis forms exactly the same number of components as the number of indicators analysed but for the analysis only the "few" first most important components are used. The first principal component accounts for the greatest variability in the dataset and each subsequent component accounts for as much of the remaining variability as possible (Dillon \& Goldstein, 1984; Dunteman, 1989; Jollife, 2010). According to the theory, the components with an eigenvalue higher than one are chosen for the next analysis or the first eigenvectors that explain a predetermined threshold of the total variability (at least 80\%) are used for the analysis. Another useful approach is a scree plot of the PCA, by which it is possible to check the inflection point of the components and, according to the inflection point, to decide about the number of main components. In our analysis the most important uncorrelated components were used for the cluster analysis (CA). CA is a technique that sorts different objects into homogenous groups of objects. The objects are similar to one another within the same cluster and dissimilar to the objects in other clusters (Loster, 2017; Megyesiova \&
Lieskovska, 2018; Kolvekova et al., 2019). Hierarchical or non-hierarchical methods are used to determine the clustering process, the process that determines which clusters should be joined at each stage (Milligan, 1995, Uprichard \& Byrne, 2012). The CA organizes the observed dataset, the observed objects (41 countries), into two or more homogenous groups, i.e. clusters.

\section{RESULTS}

The per capita pure alcohol consumption in 41 OECD and EU member states dropped moderately between 2000 and 2016 (Table 1). In 2000, on average, a person living in selected countries consumed 9.8 litres of pure alcohol; the highest share of the consumption belonged to beer (41.5\%), followed by wine (28.6\%), spirits (26.1\%), and other alcoholic beverages (3.7\%). The consumption of pure alcohol dropped to 9.3 litres per capita in 2016, with a very similar structure of alcohol consumption.

The smallest change in the share of the consumption in the time span that was analysed was achieved for the consumption of beer and the biggest change for the consumption of spirits. The decline in the proportion for the consumption of spirits was as high as 1.6 percentage points (p.p.). An increase higher than 1 p.p. was scored for the proportion of other alcoholic beverages, which increased from $3.7 \%$ in 2000 to $4.9 \%$ in 2016. The decline in the average value of pure alcohol consumption per capita in the 41 countries that were analysed and the decline in the share of spirits in the total alcohol consumption from 2000 till 2016 must be rated positively.

\begin{tabular}{|c|c|c|c|c|c|c|}
\hline Variable & Mean & Std Dev & Minimum & Maximum & Range & Median \\
\hline Alcohol consumption, total (2000) & 9.8 & 3.1 & 1.5 & 14.1 & 12.5 & 10.1 \\
\hline Beer, 2000 & 4.0 & 1.7 & 0.8 & 7.9 & 7.1 & 3.8 \\
\hline Wine, 2000 & 3.0 & 2.2 & 0.0 & 8.6 & 8.6 & 2.5 \\
\hline Spirits, 2000 & 2.4 & 1.2 & 0.5 & 6.5 & 6.0 & 2.1 \\
\hline Other alc.bever., 2000 & 0.4 & 1.2 & 0.0 & 7.6 & 7.6 & 0.0 \\
\hline Beer (\%), 2000 & 41.5 & 12.5 & 15.3 & 73.7 & 58.5 & 42.6 \\
\hline Wine (\%), 2000 & 28.6 & 17.1 & 0.3 & 72.2 & 71.9 & 28.6 \\
\hline Spirits (\%), 2000 & 26.1 & 11.4 & 4.5 & 49.3 & 44.9 & 25.8 \\
\hline Other alc.bever. (\%), 2000 & 3.7 & 12.3 & 0.0 & 73.7 & 73.7 & 0.0 \\
\hline Alcohol consumption, total (2016) & 9.3 & 2.6 & 1.3 & 15.4 & 14.1 & 9.6 \\
\hline Beer, 2016 & 3.8 & 1.4 & 0.7 & 6.9 & 6.2 & 3.9 \\
\hline Wine, 2016 & 2.7 & 1.7 & 0.1 & 6.9 & 6.8 & 2.8 \\
\hline Spirits, 2016 & 2.3 & 1.5 & 0.4 & 7.7 & 7.3 & 2.1 \\
\hline Other alc.bever., 2016 & 0.5 & 1.1 & 0.0 & 6.2 & 6.2 & 0.1 \\
\hline Beer (\%), 2016 & 41.6 & 11.9 & 18.2 & 77.0 & 58.8 & 41.4 \\
\hline Wine (\%), 2016 & 28.9 & 16.5 & 1.9 & 64.7 & 62.8 & 28.4 \\
\hline Spirits (\%), 2016 & 24.5 & 11.3 & 7.1 & 50.3 & 43.2 & 21.5 \\
\hline Other alc.bever. (\%), 2016 & 4.9 & 12.0 & 0.0 & 68.9 & 68.9 & 1.2 \\
\hline
\end{tabular}

Table 1 S Summary statistics of pure alcohol consumption in OECD and EU member states (in litres per capita)

Source: authors' own calculations based on the WHO Global Information System on Alcohol and Health and the Global Health Observatory 
Multivariate cluster analysis (CA) was chosen to detect the clusters of 41 countries using eleven selected indicators. The countries will form relatively good isolated clusters with similar stages of the selected indicators. According to the findings, the consumption of alcohol can lead to mortality, and therefore for analytical purposes indicators of alcohol consumption were combined with the age-standardized mortality rates of the population older than 15 years (15+) and life expectancies (LE). As alcohol consumption in 2000 and 2016 was chosen, the trend of alcohol consumption will also be visible in the clusters. The SDR (15+), separately for men and women, is included in the analysis. As some of the analysis shows a positive effect of the moderate and regular consumption of wine, the proportion of wine in the total per capita alcohol consumption in 2000 was also selected as an indicator for the CA. LE at birth was included in the analysis, as alcohol consumption can have a negative influence on the life expectancies in a country.

For the cluster analysis the following set of indicators was used:

$\mathrm{X}_{1}$ - pure alcohol consumption in litres per capita (year 2000), $X_{2}$ - proportion of wine consumption, in \% (year 2000),

$\mathrm{X}_{3}$ - male, SDR (15+) from liver cirrhosis per 100,000 people resulting from alcohol consumption (year 2016),

$\mathrm{X}_{4}$ - female, SDR (15+) from liver cirrhosis per 100,000 people resulting from alcohol consumption (year 2016),

$\mathrm{X}_{5}$ - male, SDR (15+) from cancer per 100,000 people resulting from alcohol consumption (year 2016),
$\mathrm{X}_{6}$ - female, SDR (15+) from cancer per 100,000 people resulting from alcohol consumption (year 2016),

$\mathrm{X}_{7}$ - male, SDR (15+) from road traffic crash deaths per 100,000 people resulting from alcohol consumption (year 2016),

$\mathrm{X}_{8}$ - female, SDR (15+) from road traffic crash deaths per 100,000 people resulting from alcohol consumption (year 2016),

$\mathrm{X}_{9}$ - life expectancy at birth, total (year 2000),

$\mathrm{X}_{10}$ - life expectancy at birth, total (year 2016),

$\mathrm{X}_{11}$ - pure alcohol consumption in litres per capita (year 2016).

The first step of the analysis was the detection of a correlation between the selected groups of indicators. The correlation analysis is a necessary tool in the checking of assumptions before the CA can be realized. CA expects uncorrelated datasets; otherwise the results of the CA will be incorrect. As expected, there exists a statistically significant correlation between more pairs of selected indicators (Table 2). However, some interesting and unexpected results were also discovered by the Pearson's correlation coefficients $r_{x y}$.

For example, something that is unexpected is the results of the $r_{x y}$ between the per capita alcohol consumption in 2000 and the SDR (15+) from liver cirrhosis resulting from alcohol consumption in 2016. For both sexes the correlation coefficient was low and statistically insignificant. On the other hand, if we take both indicators from the same year, 2016, the $r_{x y}$ is statistically significant (for males $r_{x y}=0.37$ with $p=0.018$ and for females $r_{x y}=0.54$ with $\left.p=0.0003\right)$. Thus,

\begin{tabular}{|c|c|c|c|c|c|c|c|c|c|c|c|}
\hline \multicolumn{12}{|c|}{$\begin{array}{c}\text { Pearson Correlation Coefficients, } \mathrm{N}=41 \\
\text { Prob }>|\mathrm{r}| \text { under H0: Rho }=0\end{array}$} \\
\hline & $\mathrm{X} 1$ & $\mathrm{X} 2$ & X3 & $\mathrm{X} 4$ & $\mathrm{X5}$ & $\times 6$ & $\mathrm{X7}$ & $\mathrm{X} 8$ & $\mathrm{X9}$ & $\mathrm{X} 10$ & $\mathrm{X} 11$ \\
\hline $\mathrm{X} 1$ & 1.00000 & $\begin{array}{l}0.41067 \\
0.0077\end{array}$ & $\begin{array}{c}0.26733 \\
0.0911\end{array}$ & $\begin{array}{c}0.27576 \\
0.0810\end{array}$ & $\begin{array}{l}0.53578 \\
0.0003\end{array}$ & $\begin{array}{l}0.76243 \\
<.0001\end{array}$ & $\begin{array}{l}0.10613 \\
0.5090\end{array}$ & $\begin{array}{l}0.16119 \\
0.3140\end{array}$ & $\begin{array}{c}-0.01537 \\
0.9240\end{array}$ & $\begin{array}{c}0.07651 \\
0.6345\end{array}$ & $\begin{array}{l}0.81005 \\
<.0001\end{array}$ \\
\hline$x 2$ & $\begin{array}{l}0.41067 \\
0.0077\end{array}$ & 1.00000 & $\begin{array}{l}-0.05846 \\
0.7166\end{array}$ & $\begin{array}{l}-0.11332 \\
0.4805\end{array}$ & $\begin{array}{l}0.10353 \\
0.5195\end{array}$ & $\begin{array}{c}0.26077 \\
0.0996\end{array}$ & $\begin{array}{c}-0.03080 \\
0.8484\end{array}$ & $\begin{array}{l}-0.16163 \\
0.3127\end{array}$ & $\begin{array}{c}0.30343 \\
0.0538\end{array}$ & $\begin{array}{l}0.26376 \\
0.0956\end{array}$ & $\begin{array}{c}0.15450 \\
0.3348\end{array}$ \\
\hline 3 & $\begin{array}{c}0.26733 \\
0.0911\end{array}$ & $\begin{array}{l}-0.05846 \\
0.7166\end{array}$ & 000 & $\begin{array}{l}31467 \\
0001\end{array}$ & $\begin{array}{l}0.65781 \\
<.0001\end{array}$ & $\begin{array}{l}710 \\
24\end{array}$ & $\begin{array}{l}0.63504 \\
<.0001\end{array}$ & $\begin{array}{l}0.53778 \\
0.0003\end{array}$ & $\begin{array}{l}-0.65122 \\
<.0001\end{array}$ & $\begin{array}{l}-0.70564 \\
<.0001\end{array}$ & $\begin{array}{c}0.3 \\
0 .\end{array}$ \\
\hline 4 & $\begin{array}{c}0.27576 \\
0.0810\end{array}$ & $\begin{array}{c}-0.11332 \\
0.4805\end{array}$ & 67 & 1.00000 & $\begin{array}{l}0 . \\
<\end{array}$ & 10 & 16 & $\begin{array}{l}36 \\
01\end{array}$ & $\begin{array}{r}-0.6 \\
<.0\end{array}$ & $\begin{array}{l}357 \\
01\end{array}$ & $\begin{array}{c}0.5 \\
0 .\end{array}$ \\
\hline$x 5$ & $\begin{array}{c}0.53578 \\
0.0003 \\
\end{array}$ & $\begin{array}{c}0.10353 \\
0.5195 \\
\end{array}$ & $\begin{array}{c}0.65781 \\
<.0001 \\
\end{array}$ & $\begin{array}{c}0.69871 \\
<.0001 \\
\end{array}$ & 1.00000 & $\begin{array}{c}0.71835 \\
<.0001 \\
\end{array}$ & $\begin{array}{c}0.45442 \\
0.0028 \\
\end{array}$ & $\begin{array}{c}0.48344 \\
0.0014 \\
\end{array}$ & $\begin{array}{c}-0.61512 \\
<.0001 \\
\end{array}$ & $\begin{array}{c}-0.56007 \\
0.0001 \\
\end{array}$ & $\begin{array}{r}0.64591 \\
<.0001 \\
\end{array}$ \\
\hline X6 & $\begin{array}{c}0.76243 \\
<.0001\end{array}$ & $\begin{array}{c}0.26077 \\
0.0996\end{array}$ & $\begin{array}{c}0.38710 \\
0.0124\end{array}$ & $\begin{array}{c}0.57710 \\
<.0001\end{array}$ & $\begin{array}{c}0.71835 \\
<.0001\end{array}$ & 1.00000 & $\begin{array}{c}0.25015 \\
0.1147\end{array}$ & $\begin{array}{c}0.34157 \\
0.0288\end{array}$ & $\begin{array}{c}-0.28388 \\
0.0721\end{array}$ & $\begin{array}{c}-0.25130 \\
0.1130\end{array}$ & $\begin{array}{l}0.81022 \\
<.0001\end{array}$ \\
\hline $\mathrm{X7}$ & $\begin{array}{c}0.10613 \\
0.5090 \\
\end{array}$ & $\begin{array}{c}-0.03080 \\
0.8484\end{array}$ & $\begin{array}{c}0.63504 \\
<.0001 \\
\end{array}$ & $\begin{array}{c}0.61216 \\
<.0001 \\
\end{array}$ & $\begin{array}{c}0.45442 \\
0.0028\end{array}$ & $\begin{array}{c}0.25015 \\
0.1147\end{array}$ & 1.00000 & $\begin{array}{l}0.91599 \\
<.0001\end{array}$ & $\begin{array}{c}-0.57759 \\
<.0001 \\
\end{array}$ & $\begin{array}{c}-0.66776 \\
<.0001 \\
\end{array}$ & $\begin{array}{c}0.37374 \\
0.0161 \\
\end{array}$ \\
\hline$x 8$ & $\begin{array}{c}0.16119 \\
0.3140\end{array}$ & $\begin{array}{c}-0.16163 \\
0.3127\end{array}$ & $\begin{array}{c}0.53778 \\
0.0003\end{array}$ & $\begin{array}{c}0.66236 \\
<.0001\end{array}$ & $\begin{array}{c}0.48344 \\
0.0014\end{array}$ & $\begin{array}{c}0.34157 \\
0.0288\end{array}$ & $\begin{array}{l}0.91599 \\
<.0001\end{array}$ & 1.00000 & $\begin{array}{c}-0.59164 \\
<.0001\end{array}$ & $\begin{array}{c}-0.63596 \\
<.0001\end{array}$ & $\begin{array}{r}0.53351 \\
0.0003\end{array}$ \\
\hline$x 9$ & $\begin{array}{c}-0.01537 \\
0.9240\end{array}$ & $\begin{array}{c}0.30343 \\
0.0538\end{array}$ & $\begin{array}{c}-0.65122 \\
<.0001\end{array}$ & $\begin{array}{c}-0.66874 \\
<.0001\end{array}$ & $\begin{array}{c}-0.61512 \\
<.0001\end{array}$ & $\begin{array}{c}-0.28388 \\
0.0721\end{array}$ & $\begin{array}{c}-0.57759 \\
<.0001\end{array}$ & $\begin{array}{c}-0.59164 \\
<.0001\end{array}$ & 1.00000 & $\begin{array}{c}0.94201 \\
<.0001\end{array}$ & $\begin{array}{c}-0.30528 \\
0.0523\end{array}$ \\
\hline $\mathrm{X} 10$ & $\begin{array}{c}0.07651 \\
0.6345 \\
\end{array}$ & $\begin{array}{c}0.26376 \\
0.0956\end{array}$ & $\begin{array}{c}-0.70564 \\
<.0001 \\
\end{array}$ & $\begin{array}{c}-0.70857 \\
<.0001 \\
\end{array}$ & $\begin{array}{c}-0.56007 \\
0.0001\end{array}$ & $\begin{array}{c}-0.25130 \\
0.1130 \\
\end{array}$ & $\begin{array}{c}-0.66776 \\
<.0001 \\
\end{array}$ & $\begin{array}{c}-0.63596 \\
<.0001\end{array}$ & $\begin{array}{c}0.94201 \\
<.0001 \\
\end{array}$ & 1.00000 & $\begin{array}{r}-0.2428 \\
0.1260 \\
\end{array}$ \\
\hline $\mathrm{X} 11$ & $\begin{array}{c}0.81005 \\
<.0001\end{array}$ & $\begin{array}{c}0.15450 \\
0.3348\end{array}$ & $\begin{array}{c}0.36700 \\
0.0183\end{array}$ & $\begin{array}{c}0.53790 \\
0.0003\end{array}$ & $\begin{array}{c}0.64591 \\
<.0001\end{array}$ & $\begin{array}{l}0.81022 \\
<.0001\end{array}$ & $\begin{array}{c}0.37374 \\
0.0161\end{array}$ & $\begin{array}{c}0.53351 \\
0.0003\end{array}$ & $\begin{array}{c}-0.30528 \\
0.0523\end{array}$ & $\begin{array}{c}-0.24287 \\
0.1260\end{array}$ & 1.00000 \\
\hline
\end{tabular}

Table 2 | Correlation analysis of indicators $X_{1}-X_{1}$

Source: authors' own calculations based on the WHO Global Information System on Alcohol and Health and the Global Health Observatory 
a statistically significant relation was discovered for the SDR from liver cirrhosis and alcohol consumption in the same year and not with the lagged correlation of alcohol consumption in 2000 and SDR from liver cirrhosis in 2016. A strong correlation also exists between the per capita alcohol consumption and SDR from cancer resulting from alcohol consumption for both sexes. The correlation for the indicators in 2016 was higher when compared with the correlation of alcohol consumption in 2000 and the SDR in 2016. If the correlations for men and women are compared, the association is stronger in the case of women. The Pearson's coefficient between the variables $X_{5}$ and $X_{11}$ was as high as 0.65 for men and as high as 0.81 for women (between the variables $X_{6}$ and $X_{11}$ ). The linear relationship between the per capita alcohol consumption was also higher among women with regard to the SDR from liver cirrhosis and from road traffic crash deaths. All these correlations were positive and statistically significant, which means that there exists a strong and positive relationship between alcohol consumption and mortality resulting from alcohol consumption. The higher association of $r_{x y}$ for women supports the assumption that women are at greater risk as a result of drinking alcohol. It is necessary to mention that the analyses were performed on the country level for 41 OECD and EU Member States and the results should be considered in the light of this fact.

The problem of the correlated indicator was solved with a specific multivariate technique, with principal component analysis. The results of the PCA are new uncorrelated variables, components (Jolliffe \& Cadima, 2016). The detailed results of the PCA are presented in Table 3 and Figure 1. According to the results of the PCA, the three first components explain more than $82.6 \%$ of the total variance of eleven indicators. These three most important components were used for the next step of the analysis, the cluster analysis.

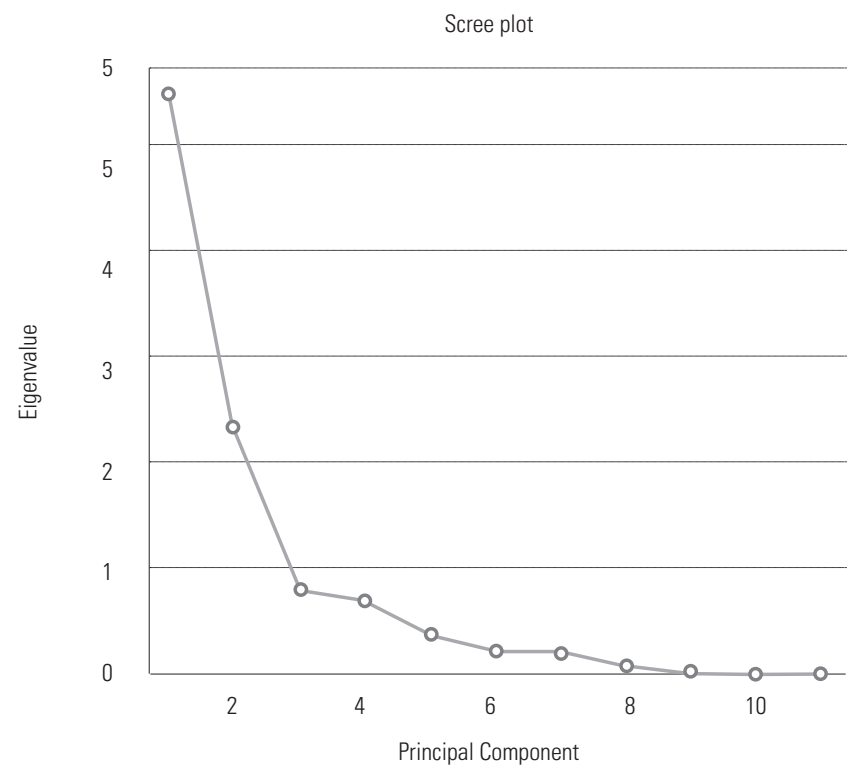

\begin{tabular}{ccccc}
\hline \multicolumn{5}{c}{ Eigenvalues of the Correlation Matrix } \\
\hline & Eigenvalue & Difference & Proportion & Cumulative \\
\hline $\mathbf{1}$ & 5.75987264 & 3.29393575 & 0.5236 & 0.5236 \\
\hline $\mathbf{2}$ & 2.46593689 & 1.60756670 & 0.2242 & 0.7478 \\
\hline $\mathbf{3}$ & 0.85837019 & 0.10671091 & 0.0780 & 0.8258 \\
\hline $\mathbf{4}$ & 0.75165929 & 0.32424613 & 0.0683 & 0.8942 \\
\hline $\mathbf{5}$ & 0.42741316 & 0.15617078 & 0.0389 & 0.9330 \\
\hline $\mathbf{6}$ & 0.27124238 & 0.05409647 & 0.0247 & 0.9577 \\
\hline $\mathbf{7}$ & 0.21714591 & 0.08814916 & 0.0197 & 0.9774 \\
\hline $\mathbf{8}$ & 0.12899676 & 0.06579341 & 0.0117 & 0.9891 \\
\hline $\mathbf{9}$ & 0.06320335 & 0.03061892 & 0.0057 & 0.9949 \\
\hline $\mathbf{1 0}$ & 0.03258443 & 0.00900942 & 0.0030 & 0.9979 \\
\hline $\mathbf{1 1}$ & 0.02357501 & & 0.0021 & 1.0000 \\
\hline & & & &
\end{tabular}

Table 3 | Eigenvalues of the Correlation Matrix (Principle Component Analysis) Source: authors' own calculations based on the WHO Global Information System on Alcohol and Health and the Global Health Observatory

Using the dendrogram (Figure 2) and Pseudo F-statistics from the CA output, the group of 41 countries was divided into six relatively good isolated clusters. The cluster centroids in Table 4 represent the main nature of the clusters.

Cluster 1 (11 countries: Australia, Cyprus, New Zealand, Canada, Greece, Finland, South Korea, Italy, the Netherlands, Spain, Switzerland)

The first cluster, together with the fourth cluster, belongs in those clusters with the highest number of countries. In this cluster the European countries joined the most developed OECD countries. Cluster 1 can be rated according to the cluster centroids as the "average" or "middle" cluster. The

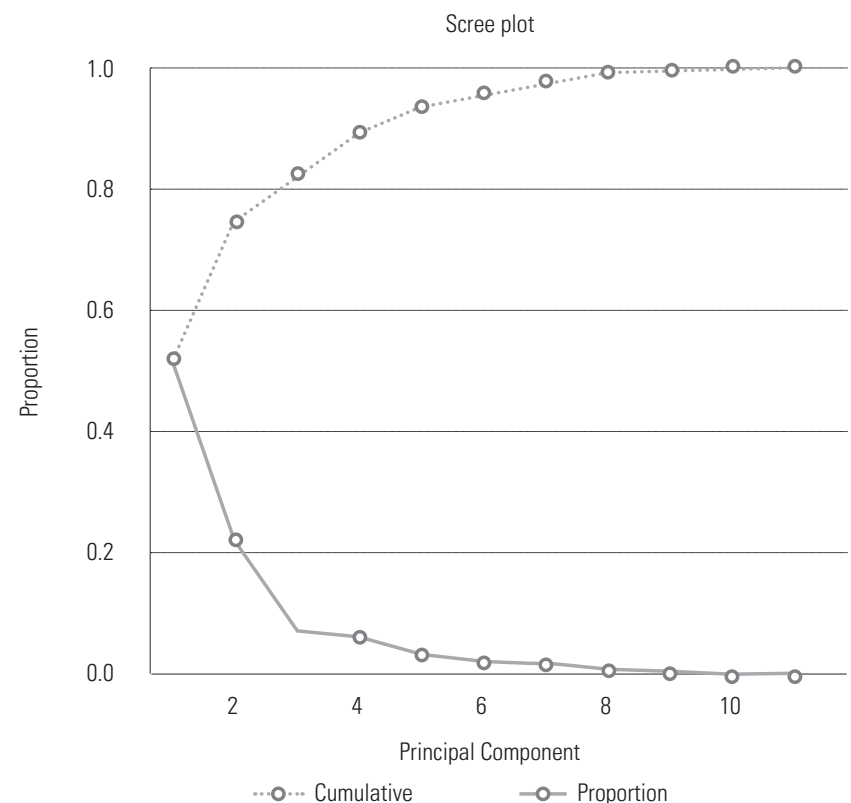

Figure 1 | Scree Plot of the Principal Component Analysis Source: authors' own calculations based on the WHO Global Information System on Alcohol and Health and the Global Health Observatory 


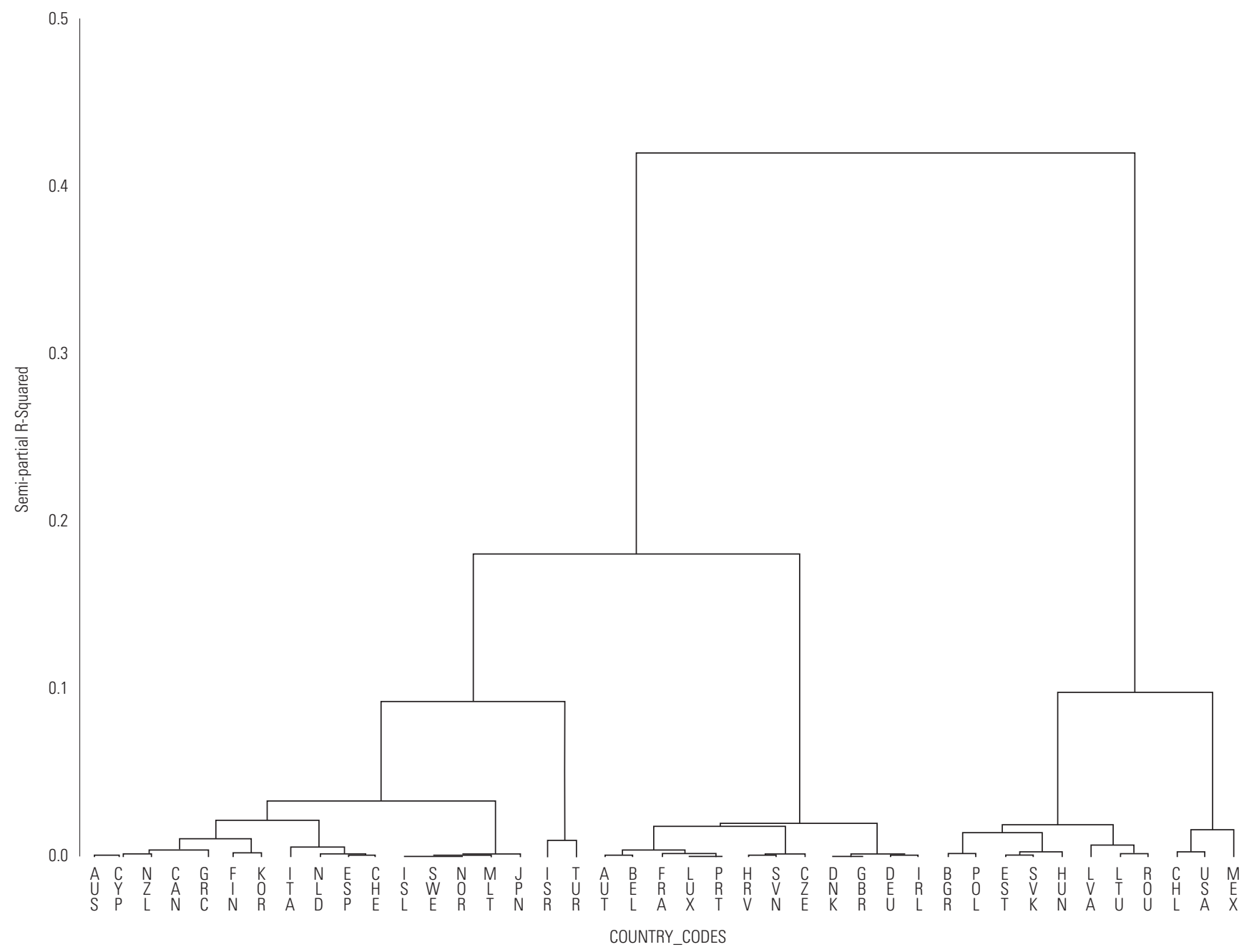

Figure 2 | Dendrogram of the cluster analysis

Source: authors' own calculations based on the WHO Global Information System on Alcohol and Health and the Global Health Observatory

\begin{tabular}{|c|c|c|c|c|c|c|}
\hline Indicator & $\begin{array}{c}\text { Cluster } 1 \\
\text { (11 countries) }\end{array}$ & $\begin{array}{c}\text { Cluster } 2 \\
\text { (5 countries) }\end{array}$ & $\begin{array}{c}\text { Cluster } 3 \\
\text { ( } 2 \text { countries) }\end{array}$ & $\begin{array}{c}\text { Cluster } 4 \\
\text { (12 countries) }\end{array}$ & $\begin{array}{c}\text { Cluster } 5 \\
\text { (8 countries) }\end{array}$ & $\begin{array}{c}\text { Cluster } 6 \\
(3 \text { countries })\end{array}$ \\
\hline $\mathrm{X} 1$ & 9,8 & 6,4 & 2,1 & 12,9 & 10,3 & 6,8 \\
\hline $\mathrm{X} 2$ & 32,1 & 21,9 & 8,3 & 37,9 & 22,1 & 21,0 \\
\hline X3 & 8,6 & 4,7 & 4,4 & 14,5 & 25,3 & 23,2 \\
\hline X4 & 2,4 & 1,7 & 1,0 & 4,3 & 8,2 & 5,4 \\
\hline $\mathrm{X5}$ & 12,7 & 10,4 & 5,6 & 18,0 & 28,3 & 8,7 \\
\hline X6 & 3,9 & 3,0 & 0,8 & 5,3 & 5,6 & 2,7 \\
\hline $\mathrm{X7}$ & 3,8 & 2,0 & 1,7 & 4,1 & 7,0 & 8,3 \\
\hline $\mathrm{X} 8$ & 0,8 & 0,4 & 0,2 & 0,8 & 1,5 & 1,6 \\
\hline X9 & 78,6 & 79,5 & 74,6 & 77,1 & 71,8 & 76,2 \\
\hline $\mathrm{X} 10$ & 82,2 & 82,6 & 79,4 & 81,1 & 76,1 & 78,2 \\
\hline X11 & 8,5 & 7,1 & 2,0 & 10,9 & 11,7 & 7,4 \\
\hline
\end{tabular}

Table 4 | Cluster centroids of cluster analysis

Source: authors' own calculations based on the WHO Global Information System on Alcohol and Health and the Global Health Observatory

per capita alcohol consumption of these countries was lower than 10 litres in 2000 and dropped to 8.5 litres by 2016 . Thus, the decline in the per capita alcohol consumption is very positive for these groups of countries. The life expec- tancies, both in 2000 and 2016, are very high, being the second largest among the clusters. The SDR (15+) resulting from alcohol consumption is in the middle compared with the other clusters. 
Cluster 2 (five countries: Iceland, Sweden, Norway, Malta, Japan)

In 2000 these countries achieved the second lowest level of per capita alcohol consumption (6.4 litres), but unfortunately, they faced an increase in alcohol consumption by $11.7 \%$ between 2000 and 2016. The growth of alcohol consumption is a negative signal, as the very low SDR resulting from alcohol consumption can increase in the very near future. The SDR (15+) resulting from alcohol consumption leading to road traffic crash deaths and liver cirrhosis in 2016 belonged among the smallest ones among the clusters. Life expectancies were the highest in 2000 and in 2016, which means that the standard of living, development status, lifestyle, and healthcare system in these countries are very high.

\section{Cluster 3 (two countries: Israel, Turkey)}

For the two countries joined into a separate cluster a very low consumption of pure alcohol per capita is typical. Religion plays a strong role in the consumption of alcohol in a society. This fact may be one of the main reasons why the per capita alcohol consumption in Cluster 3 reached only 2.1 litres in 2000 and 2.0 litres in 2016. Not only was the alcohol consumption the lowest in this cluster, but as a result of the low alcohol consumption the SDR (15+) resulting from alcohol consumption achieved the lowest levels too. Both countries should be rated very positively because of their very low alcohol consumption, which resulted in the lowest mortality resulting from alcohol consumption.

Cluster 4 (12 countries: Austria, Belgium, France, Luxembourg, Portugal, Croatia, Slovenia, Czechia, Denmark, the United Kingdom, Germany, Ireland)

For the countries in the largest cluster a very high alcohol consumption was typical. In 2000 the per capita consumption of pure alcohol was the highest (12.9 litres). What should be rated positively is that they exhibited the greatest decline in alcohol consumption. The relative decline was higher than $15 \%$ and so the per capita consumption dropped by about two litres between 2000 and 2016. The percentage of wine consumption in the total alcohol consumption was the highest (37.9\%). Although the alcohol consumption in 2000 was the highest in this group of countries, the mortality resulting from alcohol consumption was significantly lower compared with the fifth cluster. In particular, the SDR (15+) resulting from alcohol consumption among men for liver cirrhosis and cancer was by ten deaths per 100,000 people lower than in cluster 5 . It is a significant difference that should be further investigated in order to discover what the main reasons for this difference are. It is necessary to say that more developed countries joined together in the fourth cluster and therefore the lower SDR resulting from alcohol consumption in this cluster may be caused by more facts; for example, it may depend on the quality of the healthcare system, a cancer prevention programme, or the lifestyle of the population, but a higher consumption of wine (as a percentage of total consumption) could also play some role in the lower mortality resulting from alcohol consumption.
Naturally, some other factors could also play a role, which is why, despite having the highest per capita alcohol consumption in 2000, the mortality rates resulting from alcohol consumption are not the highest ones either.

Cluster 5 (eight countries: Bulgaria, Poland, Estonia, Slovakia, Hungary, Latvia, Lithuania, Romania)

Together, the former Communist countries, the "new" EU Member States, created a cluster with very high mortality rates resulting from alcohol consumption. Unfortunately, the per capita consumption of pure alcohol in these countries did not develop very positively. It increased from a level of 10.3 litres in 2000 to 11.7 litres in 2016. Out of all six clusters, they reached the highest relative growth rate of alcohol consumption, as the per capita alcohol consumption jumped by $14 \%$ in the time span that was analysed. These countries definitely have a very high mortality rate resulting from alcohol consumption as a result of liver cirrhosis and cancer, especially for men. What is also typical for these countries is the highest differences in the mortality rates between the sexes as a result of alcohol consumption. The life expectancy in these former Communist countries was the lowest in 2000 and also in 2016.

Cluster 6 (three countries: Chile, the United States, Mexico)

The last cluster consists of three OECD countries, the countries from the North and South American Continents. The per capita alcohol consumption between 2000 and 2016 increased from 6.8 to 7.4 litres, which represents a negative trend regarding the consumption of pure alcohol. The SDR (15+) resulting from liver cirrhosis caused by alcohol consumption were the second largest of all the clusters. The rates of mortality from road traffic crashes caused by alcohol consumption, which were the highest ones for men and also for women, must be rated very negatively. These countries should focus more on the prevention of alcohol consumption while driving, which could help to reduce the high mortality rate connected with road traffic crashes.

\section{DISCUSSION}

The selected indicators for the cluster analysis were chosen with respect to studies that discuss the association between heavy alcohol consumption and higher mortality, and which try to explain the possible linkage between some illnesses and harmful alcohol consumption or between alcohol consumption and lower life expectancies. On the other hand, the fact that moderate regular drinking, especially the consumption of wine, has some beneficial effects on health, was considered an important part of the paper. The proportion of wine consumption was therefore chosen as one of the indicators for the multivariate analysis. The question was whether, in those countries with a high (or higher) proportion of wine consumption, any signs of "better" results in the variables that were analysed were achieved. For example, was the SDR for selected mortality rates resulting from alcohol consumption lower in these countries or not? 
The evidence of that interest was affirmed by the cluster analysis and by joining twelve countries into a common cluster. What was typical of these countries was the highest pure alcohol consumption in 2000 and the highest proportion of wine consumption. The highest per capita alcohol consumption could be associated with the highest SDR (15+) resulting from alcohol consumption, but these countries had a "middle" SDR among the clusters. Naturally, some other factors could play a role in these "middle" SDR, but according to the variables that were analysed, the highest proportion of wine consumption may be one of the reasons why the SDR resulting from alcohol consumption were lower than expected.

Two countries, namely Czechia and Slovakia, did not appear in one common cluster. It was a surprise, since Czechs and Slovaks have a common history and similar living conditions and/or living standards, which led to the expectation that these two countries would be joined into the same cluster. But Czechia appeared in the largest cluster, together with the "old" EU member states, while Slovakia created a cluster together with the "new" EU countries or what are called the former Communist countries. The biggest difference between the cluster in which Czechia appeared is a higher per capita alcohol consumption in 2000 compared to the cluster in which Slovakia appeared. Another significant difference between both clusters was detected in terms of the proportion of wine in total alcohol consumption. The cluster that includes Czechia reached the highest proportion of the consumption of wine compared with all the other clusters. The highest proportion of wine consumption may belong among the reasons why, despite a higher alcohol consumption, the SDR (15+) resulting from alcohol consumption were not extremely high. The SDR resulting from alcohol consumption was much higher in those clusters where the proportion of wine consumption was significantly lower, for example also in the cluster in which Slovakia appeared.

\section{CONCLUSIONS}

The main aim of the analysis was to create clusters of countries using a set of indicators. The indicators represent a mix of variables where it is possible to see the impact of alcohol consumption on mortality or life expectancies. Using the cluster analysis, the 41 OECD and EU countries were grouped into six clusters. The cluster that included only two countries, namely Israel and Turkey, achieved the lowest pure alcohol consumption per capita. This cluster confirms that very low alcohol consumption is associated with very low mortality rates resulting from alcohol consumption. The cluster with the highest alcohol consumption was formed only of former Communist countries, where, on average, a person consumed 10.3 litres of pure alcohol in 2000. Unfortunately, this indicator even increased till 2016, to 11.7 litres per capita. The highest SDR (15+) resulting from alcohol consumption were typical of the "new" EU member countries. What was significantly higher was the mortality for men resulting from alcohol consumption leading to liver cirrhosis and from cancer. The lower living standard in these countries also resulted in the lowest life expectancies at birth. The results of the cluster with the highest number of countries were very interesting. The twelve countries that formed the fourth cluster had the highest consumption per capita of pure alcohol in 2000 (12.9 litres). But what is interesting is that they did not display the highest mortality rates resulting from alcohol consumption. The SDR (15+) were in the "middle" between the clusters. What was also typical of the countries in this cluster was the highest proportion of wine consumption, which reached 38\%. Regular light consumption of wine is associated with some positive effects on one's health condition (Castaldo et al., 2019). One of the reasons why, despite the highest alcohol consumption. the mortality rates were not the highest ones, may be the structure of the consumption of alcohol. The population in these countries prefers to drink wine instead of spirits or beer. But other factors that were not included into the analysis could play a positive role in the lower mortality, especially the very good healthcare system in these countries, better preventive programmes for the early detection of cancer, and the lifestyle of the population living in these developed countries. More research is therefore needed in the area of the effect of the consumption of light wine on lower mortality rates resulting from alcohol consumption. For the countries from North and South America that were connected in one cluster, it is necessary to think more about the prevention of alcohol consumption while driving. Despite their lower alcohol consumption, these three countries (Chile, the United States, and Mexico) displayed the highest mortality rates resulting from road traffic crashes caused by alcohol consumption. With a better prevention programme, including penalties for drunk drivers, the SDR (15+) could be pushed down to much lower values.

\section{Authors' contributions: Silvia Megyesiová and Beáta Gavurová designed the study and proposed the study design. Silvia Megyesiová performed the statistical analysis; Silvia Megyesiová and Beáta Gavurová participated in} the interpretation of the data and the preparation of the manuscript and were responsible for the literature review and for drafting of the introduction to the article. Both authors contributed to the article equally and approved the final version of the manuscript.

Declaration of interest: There is no conflict of interest involved in this research. 


\section{REFERENCES}

Castaldo, L., Narváez, A., Izzo, L., Graziani, G., Gaspari, A., Di Minno, G., \& Ritieni. A. (2019). Red Wine Consumption and Cardiovascular Health. Molecules, 24(19), 3626. doi:10.3390/molecules24193626

Castelnuovo, A. D. (2006). Alcohol Dosing and Total Mortality in Men and Women. Archives of Internal Medicine, 166(22), 2437. doi:10.1001/ archinte.166.22.2437Dillon, W. R., \& Goldstein, M. (1984). Multivariate analysis: methods and applications. John Wiley \& Sons: New York.

Dunteman, G. H. (1989). Principal Component Analysis. SAGE: Newbury Park.

Gavurova, B., Kubak, M., \& Kulhanek, A. (2019). Age-gender mortality study on alcohol-induced deaths in Slovakia. Central European Journal of Public Health 27(Supplement). doi:10.21101/cejph.a5765

German, J. B., \& Walzem, R. L. (2000). The Health Benefits of Wine. Annual Review of Nutrition, 2011), 561-593. doi:10.1146/annurev.nutr.20.1.561

Grabauskas, V., Prochorskas, R., \& Veryga, A. (2009). Associations between mortality and alcohol consumption in the Lithuanian population. Medicina, 45(12), 1000. doi:10.3390/medicina45120128

Han, M. A. (2019). Associations between Harmful Experiences from Alcohol Use of Others and Mental Health in Korean Adolescents. International Journal of Environmental Research and Public Health, 16(21), 4240. doi: 10.3390/ijerph16214240

Huang, J., Li, R., Huang, S., Sia, H., Chen, Y., \& Tang, F. (2015). Lifestyle Factors and Metabolic Syndrome among Workers: The Role of Interactions between Smoking and Alcohol to Nutrition and Exercise. International Journal of Environmental Research and Public Health, 12(12), 15967-15978. doi:10.3390/ijerph121215035

Ikehara, S., \& Iso, H. (2020). Alcohol consumption and risks of hypertension and cardiovascular disease in Japanese men and women. Hypertension Research. doi:10.1038/s41440-020-0417-1

Jolliffe, I. T. (2010). Principal Component Analysis; Springer: New York.

Jolliffe, I. T., \& Cadima, J. (2016). Principal component analysis: A review and recent developments. Philosophical Transactions of the Royal Society A: Mathematical, Physical and Engineering Sciences, 374(2065), 20150202. doi:10.1098/rsta.2015.0202

Kolvekova, G., Liptakova, E., Strba, L, Krsak, B., Sidor, C., Cehlar, M., Khouri, S., \& Behun, M. (2019). Regional Tourism Clustering Based on the Three Ps of the Sustainability Services Marketing Matrix: An Example of Central and Eastern European Countries. Sustainability, 11(2), 400. doi:10.3390/su11020400

König, C., Skriver, M. V., Iburg, K. M., \& Rowlands, G. (2018). Understanding Educational and Psychosocial Factors Associated with Alcohol Use among Adolescents in Denmark; Implications for Health Literacy Interventions. International Journal of Environmental Research and Public Health, 15(8), 1671. doi:10.3390/ijerph15081671

Loster, T. (2017). Comparison of Results of Selected Clustering Methods on Real Data Set. $11^{\text {th }}$ International Days of Statistics and Economics. Proceedings Paper, pp. 886-896. Melandrium, Czech Republic. ISBN 978-80-87990-12-4.

Megyesiova, S., \& Lieskovska, V. (2018). Analysis of the Sustainable Development Indicators in the OECD Countries. Sustainability, 10 (12), 4554. doi:10.3390/su10124554

Mravčík, V., Chomynová, P., Nechanská, B., Černíková, T., \& Csémy, L. (2019). Alcohol use and its consequences in the Czech Republic. Central European Journal of Public Health, 27 (Supplement). doi:10.21101/cejph.a5728

Milligan, G. W. (1995). Cluster analysis; College of Business, Ohio State University: Columbus.

NHS. The risks of drinking too much. Available online: https://www.nhs.uk/live-well/ alcohol-support/the-risks-of-drinking-too-much/ (accessed on 10 December 2019)

NIAAA. National Institute on Alcohol Abuse and Alcoholism. Alcohol's Effects on the Body. Available online: https://www.niaaa.nih.gov/alcohols-effects-body (accessed on 10 December 2019)
OECD. Health risks - Alcohol consumption - OECD Data. Available online: https://data.oecd.org/healthrisk/alcohol-consumption.htm (accessed on 10 December 2019)

Rehm, J., \& Roerecke, M. (2017). Cardiovascular effects of alcohol consumption Trends in Cardiovascular Medicine, 278), 534-538. doi:10.1016/j.tcm.2017.06.002

Rehm, J., \& Shield, K. D. (2019). Global Burden of Alcohol Use Disorders and Alcohol Liver Disease. Biomedicines, 74), 99. doi:10.3390/biomedicines7040099

Roerecke, M., \& Rehm, J. (2012). The cardioprotective association of average alcohol consumption and ischaemic heart disease: A systematic review and meta-analysis. Addiction, 10777), 1246-1260. doi:10.1111/j.1360-0443.2012.03780.x

Statistics solutions. Conduct and Interpret a Factor Analysis. Available online: http://www.statisticssolutions.com/factor-analysis-2/ (accessed on 30 November 2019)

Uprichard, E., \& Byrne, D. S. (2012). Cluster analysis. Logic and classics; SAGE: London.

WHO. Global Information System on Alcohol and Health (GISAH). Available online: http://apps.who.int/gho/data/?showonly=GISAH\&theme=main (accessed on 30 November 2019)

WHO (2018). Global status report on alcohol and health 2018. Geneva, World Health Organization. 2018.

WHO. The Global Health Observatory. The data repository. Available online: https://www.who.int/data/gho (accessed on 30 November 2019) 